\title{
Detecting charging state of ultra-fine particles: instrumental development and ambient measurements
}

\author{
L. Laakso ${ }^{1}$, S. Gagné ${ }^{1}$, T. Petäjä ${ }^{1}$, A. Hirsikko ${ }^{1}$, P. P. Aalto ${ }^{1}$, M. Kulmala ${ }^{1}$, and V.-M. Kerminen ${ }^{2}$ \\ ${ }^{1}$ Department of Physical Sciences, P.O. Box 64, 00014 University of Helsinki, Finland \\ ${ }^{2}$ Finnish Meteorological Institute, Research and Development, P.O. Box 503, 00101 Helsinki, Finland
}

Received: 25 April 2006 - Published in Atmos. Chem. Phys. Discuss.: 13 July 2006

Revised: 30 January 2007 - Accepted: 19 February 2007 - Published: 27 February 2007

\begin{abstract}
The importance of ion-induced nucleation in the lower atmosphere has been discussed for a long time. In this article we describe a new instrumental setup - Ion-DMPS - which can be used to detect contribution of ion-induced nucleation on atmospheric new particle formation events. The device measures positively and negatively charged particles with and without a bipolar charger. The ratio between "charger off" to "charger on" describes the charging state of aerosol particle population with respect to equilibrium. Values above one represent more charges than in an equilibrium (overcharged state), and values below unity stand for undercharged situation, when there is less charges in the particles than in the equilibrium.

We performed several laboratory experiments to test the operation of the instrument. After the laboratory tests, we used the device to observe particle size distributions during atmospheric new particle formation in a boreal forest. We found that some of the events were clearly dominated by neutral nucleation but in some cases also ion-induced nucleation contributed to the new particle formation. We also found that negative and positive ions (charged particles) behaved in a different manner, days with negative overcharging were more frequent than days with positive overcharging.
\end{abstract}

\section{Introduction}

New particle formation is taking frequently place in the global atmosphere worldwide (Kulmala et al., 2004). Despite many observations, however, the exact nucleation mechanisms still remain an open question. Several nucleation pathways including ion-induced, ternary, binary and kinetic nucleation had been proposed, but the relative importance of these processes in different environments is still unknown.

Correspondence to: L. Laakso

(lauri.laakso@iki.fi)
Ternary and binary nucleation refer to the number of vapors participating in the nucleation process, whereas ion-induced nucleation refers to the presence of charges in nucleation (Weber et al., 1996; Laakso et al., 2002). Thus, both binary and ternary nucleation can be either ion-induced or neutral. A proposed particle nucleation mechanism is the activation of stable clusters (Hoppel et al., 1994; Kulmala et al., 2000, 2006), which can be either neutral or ion clusters.

Most studies on atmospheric nucleation are based on utilization of electric charges and electric fields (for an overview, see e.g. Flagan (1998)). Such devices include ion mass spectrometers, ion-spectrometers and Differential Mobility Particle Sizer (DMPS) (Aalto et al., 2001; Weber et al., 1995; Winklmayr et al., 1991). Ion mass spectrometers have been used successfully in the studies of new particle formation in the upper atmosphere (Eichkorn et al., 2002). Recent developments in atmospheric measurements are the commercially available ion spectrometers which detect ion or charged aerosol distributions from cluster ion sizes up to the Aitken mode (Laakso et al., 2004). Typically, ion spectrometers measure both polarities (Misaki, M. , 1950, 1961).

The most common aerosol sampling instrument utilizing an electric field is the Differential Mobility Analyzer (DMA) in a DMPS-system. In the DMA aerosol particles of certain mobility are separated from an air flow. In the DMPS system, only the charged fraction of particles is measured. The equilibrium charge on particles is provided by a radioactive bipolar or by a unipolar corona charger. The total particle number concentration is obtained after a mathematical inversion of the charged fraction. Since only few percent of particles in small sizes are charged, this inversion procedure is very sensitive to understanding the charging probability of particles.

The charged fraction can be calculated from different theories, most widely-used are the semi-empirical theories by Hoppel and Frick (1986) and Wiedensohler (1988) as well as the flux-matching theory by Fuchs and Sutugin (1970).

Published by Copernicus GmbH on behalf of the European Geosciences Union. 


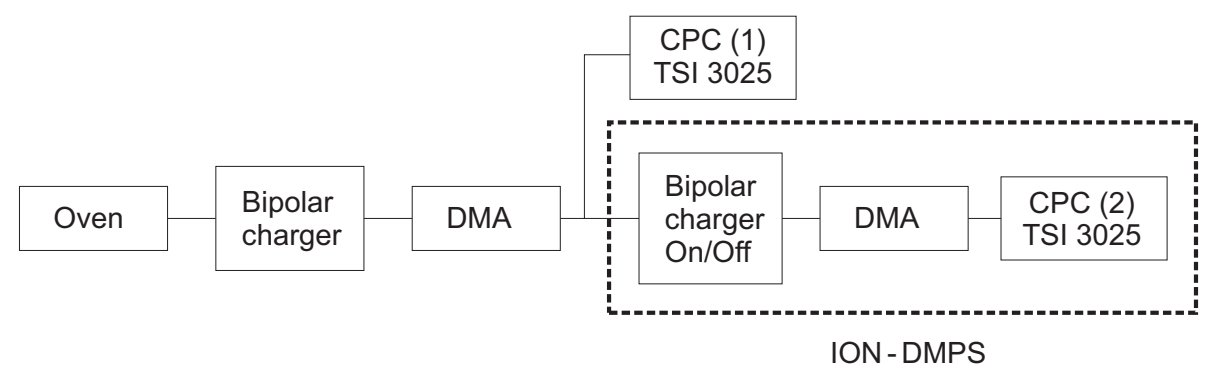

Fig. 1. A schematic figure of measurement apparatus and the laboratory setup. In ion-DMPS (boxed with dashed line) ultrafine particles are either directed to the Differential Mobility Analyzer (DMA) via bi-polar charger (Ni-63), where the sample reached an equilibrium charge distribution, or the radioactive source is isolated from the sample flow and the charge distribution is measured as it is in ambient air. The DMA has a switchable high voltage supply, which enables measurements of both negative and positive polarities. For laboratory verifications, monomodal test aerosol was produced with a heated oven and directed to the ion-DMPS setup and a reference instrument (TSI model 3025) in order to determine total number concentration of generated aerosol particles and to monitor constant output of the generator.

Unfortunately, despite numerous laboratory studies, the particle charging probability in the atmosphere is not wellknown, especially for the smallest particle sizes (Reischl et al., 1996). Thus, if we are interested in freshly-formed nanoparticles, more information on atmospheric charging probabilities is needed (Hussin et al., 1983; Reischl et al., 1996).

In addition to being necessary for interpretation of instrumental results, electric charges on particles may also carry information about the nucleation processes. In their earlier study Vana et al. (2006) found out that during nucleation bursts particles often carry more charges than in particles in electrical equilibrium. In case of ion-induced nucleation, new particles are formed electrically charged, whereas in case of neutral nucleation particles do not initially carry any charges. Thus, depending on nucleation mechanism, the charging state of particles may deviate from that in the charge equilibrium. When nucleated particles grow, they will finally reach the electrical equilibrium (Vana et al., 2006). In this study, we use the term steady-state charging probability when referring to the fraction of charged particles in the equilibrium state. The term charged fraction tells how large is the percentage of charged particles at a certain size. The term charging state refers to the charged fraction with respect to the charged fraction in the equilibrium state (charging probability). If there are fewer charged particles than there would be in the equilibrium state, the charging state of the particles is called undercharged. If the number of charged particles exceeds the equilibrium value, the particles are overcharged.

In this work, we present a new instrumental setup which can be used to define charging state of aerosol particles. A preliminary version of this device was utilized already by Mäkelä et al. (2003) but the results remained unpublished. A similar, but less sophisticated than the current version of this device was also described by Laakso et al. (2004). After describing the instrument and its measurement principles, we present a laboratory verification of the instrument. Then we apply the instrument to study ambient new particle formation events. Finally, the results and their consequences are discussed.

\section{Instrumentation}

\subsection{Ion-DMPS}

The ion-Differential Mobility Particle Sizer (ion-DMPS) is based on a well-defined aerosol sizing instrumentation concentrating on the ultra-fine particle size range $(<15 \mathrm{~nm}$ in diameter (Aalto et al., 2001). A schematic picture of the instrument is presented in Fig. 1 (boxed with dashed line). First, aerosol particles are led to a bipolar charger (Ni-63) that can be switched on and off. Next, they are led trough a conventional Differential Mobility Analyzer (DMA, length $0.109 \mathrm{~m}$, (Winklmayr et al., 1991) with a switchable twopolarity high voltage power supply. By changing the polarity in the DMA, we were able to measure either positively- or negatively-charged particles. The DMA was typically operated with a closed loop sheath flow (Jokinen and Mäkelä, 1997) with $151 \mathrm{~min}^{-1}$ sheath and $31 \mathrm{~min}^{-1}$ aerosol flow rates. The size segregated particles were detected with a TSI 3025 (Stolzenburg and McMurry, 1991) ultrafine particle counter (CPC). Given the minimum and maximum voltage, flow rates, and counting efficiency of the CPC, this corresponded to a size range of approximately 3 to $15 \mathrm{~nm}$ in electrical mobility equivalent diameter.

The charger is a rectangular brass construction, with dimensions of $100 \mathrm{~mm}, 27 \mathrm{~mm}$ and $15 \mathrm{~mm}$ for length, width and height, respectively. With the aerosol sample flow rate of $2.51 \mathrm{~min}^{-1}$, the residence time inside the charger is approximately 1 second. The $\beta$-active Nickel-63 foil is attached to a turning cylinder on top of the charger body. The cylinder is attached to a stepper motor, which turns the foil either towards the sample flow (charger on) or in face with the inside wall (charger off). The dimensions and activity is 
comparable to commercially available Krypton- 85 neutralizers (TSI-3077A). The stopping distance in air for $\beta$-radiation from Ni-63 is considerably shorter than that for a Krypton85 , thus the Ni-63 effectively distributes its energy within the charger.

Small adjustments to a conventional instrument enabled us to measure aerosol particle size distribution in four different operating modes: 1) the charger was on and the DMA had a negative polarity; 2) the charger was off and the DMA had a negative polarity; 3 ) the charger was on and the DMA had a positive polarity; 4) the charger was off and the DMA had a positive polarity. For each operation mode, a size scan with pre-defined intervals was carried out.

\subsubsection{Laboratory verification of ion-DMPS}

The ion-DMPS was tested in a laboratory prior to deployment under field conditions. Several tests were performed with monodisperse silver particles (transport efficiency, neutralization efficiency) and monodisperse ammonium sulphate (neutralization). Polydisperse silver and ammonium sulphate was used in the charge equilibrium experiments.

The laboratory setup is depicted in Fig. 1. Polydisperse ultrafine silver particles were generated with an oven (Carbolite Furnaces MTF 12/388). Ammonium sulphate was generated from liquid solution with Topas ATM 220 aerosol generator (Topas GmbH, Dresden, Germany). An equilibrium charge distribution was obtained with a bipolar NI-63 charger and from the resulting particle population a monodisperse selection was extracted with a Vienna-type Differential Mobility Analyser (DMA, length $0.109 \mathrm{~m}$, Winklmayr et al. (1991)). The sheath flow was set to $201 \mathrm{~min}^{-1}$ and aerosol flow to $11 \mathrm{~min}^{-1}$. The aerosol sample was then separated between the ion-DMPS and TSI model 3025 Ultrafine Condensation Particle (UCPC, Stolzenburg and McMurry (1991)), the latter of which was used as a reference instrument for absolute particle concentration. In addition, with the aid of the reference instrument, it was also possible to normalize small fluctuations in the aerosol generation system.

\subsubsection{Transport efficiency}

The purpose of the ion-DMPS is to determine the charging state of ultra-fine particles. Although knowing the absolute particle concentration is not essential in doing that, the initial ultra-fine particle concentration has to be large enough to penetrate through the system and to give a reliable concentration reading during the counting. The transport efficiency through the ion-DMPS was determined experimentally with monodisperse silver particles ranging from 3 to $40 \mathrm{~nm}$ in electrical mobility equivalent diameter. The transport efficiency was a steep exponential curve. Roughly $75 \%$ of $20 \mathrm{~nm}$ particles penetrated the setup, whereas only $25 \%$ of $5 \mathrm{~nm}$ particles survived. In the normal operation range of 3$15 \mathrm{~nm}$, the transport efficiency of the setup is 15 to $65 \%$. The
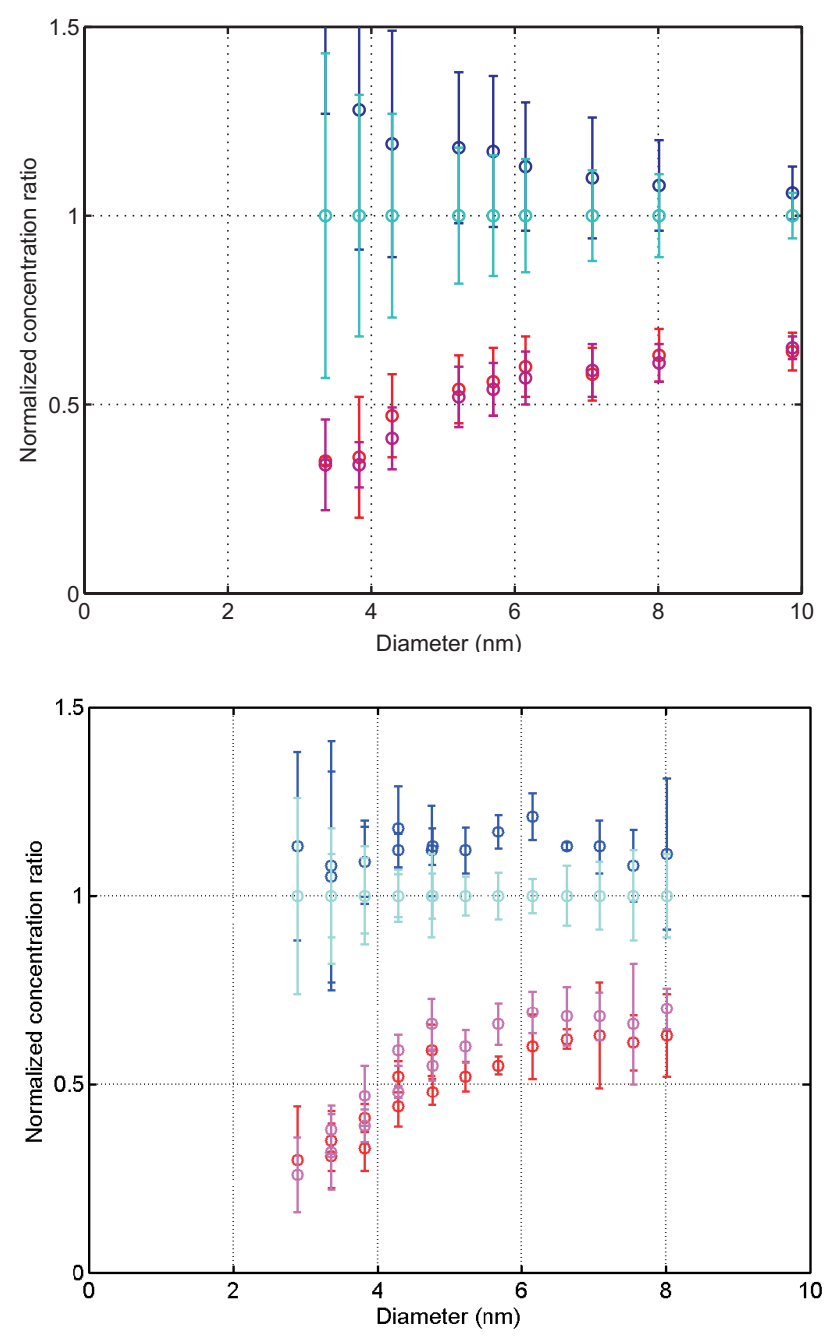

Fig. 2. Charge balance of laboratory generated ammonium sulphate (upper panel) and silver (lower panel) particles determined with the Ion-DMPS. All the ion-DMPS concentrations were normalized with respect to the concentration of negative, non-neutralized particles (cyan). Error bars are standard deviations for a given particle size i.e. variability of the concentration ratios between consecutive experiments conducted on a same day. Colors: dark blue: negative neutralized; Cyan: negative; Magenta: positive; Red: positive neutralized.

cut-size, i.e. the diameter at which the transport efficiency is $50 \%$, was $7.2 \mathrm{~nm}$. This corresponds to a ideal laminar flow diffusion loss (Baron and Willeke, 2001) of $16.4 \mathrm{~m}$ of a circular tube.

Assuming Poisson-counting statistics for the CPC and 15 second-integration time this will lead to $42 \%$ and $13 \%$ statistical error for concentrations of $0.1 \mathrm{~cm}^{-3}$ and for $1 \mathrm{~cm}^{-3}$, respectively. For this reason, concentrations below $0.1 \mathrm{~cm}^{-3}$ were neglected in the charging state estimations. One has to bear in mind that the losses are, however, not as crucial to the performance of the ion-DMPS as they are in case of 

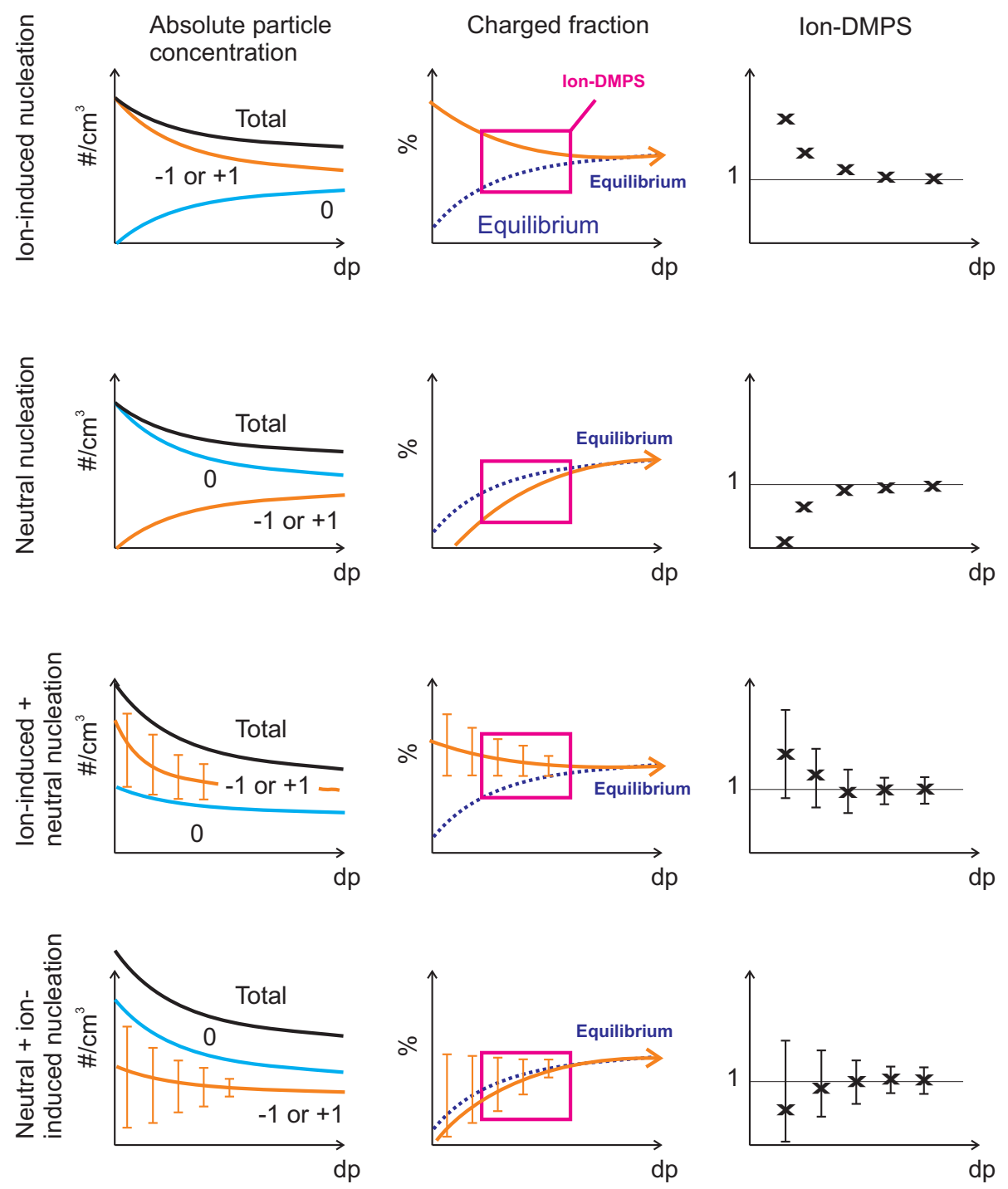

Fig. 3. A schematic figure showing the contributions of ion-induced and neutral nucleation. On the left column: absolute concentrations; middle column: charged fraction and equilibrium charged fraction; right column: fraction obtained from ion-DMPS. First row represent situation with pure ion-induced nucleation, second line pure neutral nucleation. Third line is a combination of ion-induced nucleation with a domination of ion nucleation whereas fourth line is a combination of neutral and ion-induced nucleation with dominating neutral nucleation. Bars in two lowermost lines represent upper and lower ends of ion-induced fraction and corresponding charging states.

a normal size distribution instrument. In the ion-DMPS, the desired information is the ratio between the concentrations of particles measured in four different operation modes, which are exposed to the same losses despite their polarities or the number of charges.

\subsubsection{Charge balance and neutralization efficiency}

A charge balance of laboratory-generated particles was determined with the ion-DMPS for polydisperse ammonium sulphate and silver particles (Fig. 2) by-passing the DMA in the laboratory setup. All the ion-DMPS concentrations were normalized with respect to the concentration of negative, non-neutralized particles (cyan line in Fig. 2).
As neutralized, polydisperse particles were sampled with the ion-DMPS, several features were detected. First, switching on the ion-DMPS charger increased the concentration of sub- $10 \mathrm{~nm}$ particles by approximately $10 \%$ in comparison with corresponding non-neutralized negative particle concentration. This effect was more pronounced in the ammonium sulphate experiments, in which the concentration enhancement was substantially larger than $10 \%$ for $<6 \mathrm{~nm}$ particles. This is due to the particle generation setup, which is not able to produce enough sub- $6 \mathrm{~nm}$ particles from liquid solution. Oven-generated silver particle concentration is higher and thus the ratio is more reliable down to $3 \mathrm{~nm}$ in size. 

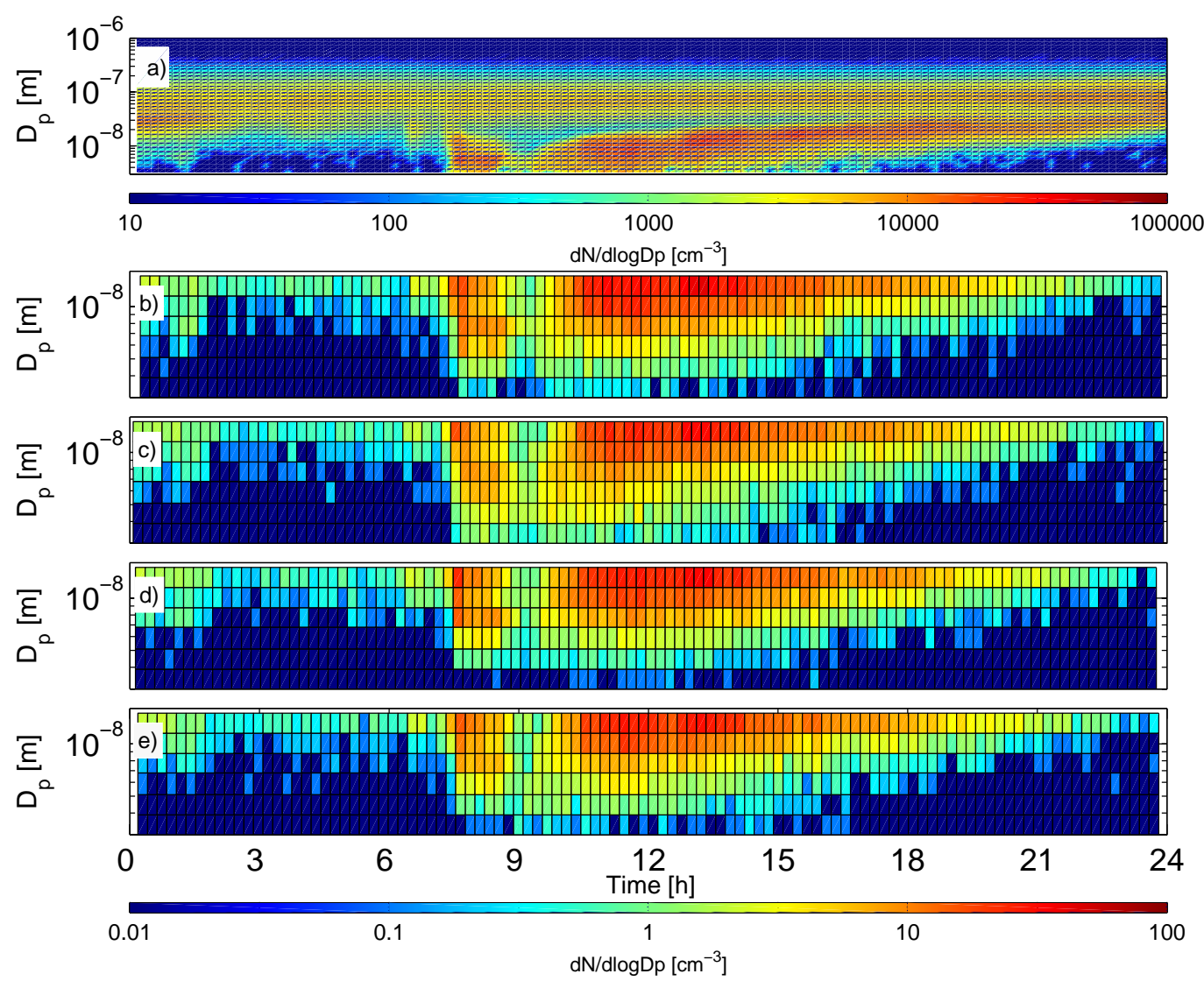

Fig. 4. Data on the distribution on the 21 May 2005: (a) Size distribution in time of all submicron particles measured with a DMPS, (b) size distribution in time of the negative neutralized ions, (c) negative natural ions, (d) positive neutralized ions, and (e) positive natural ions measured with the ion-DMPS. Mind the different scales for concentration and particle diameters in DMPS and ion-DMPS.

Normalized concentration ratios were higher in the case of negative polarity as compared with the positive concentration ratios. This is due to higher mobilities of negative cluster ions, which attach to the sampled particles in the ion-DMPS charger. This has been seen in earlier experiments (Wiedensohler, 1988) as well as using theoretical calculations (Fuchs and Sutugin, 1970; Hoppel and Frick, 1986). As the particle size decreased, the absolute charging efficiency decreased for both polarities. Since the data are normalized to nonneutralized negative concentration, the non-neutralized ratio fluctuate around unity and the neutralized ratio has an average $10 \%$ offset. On the other hand, the ratio between the negative and positive charging efficiencies did not remain the same in our experiments i.e. ratios of positive concentrations (Fig. 2) had a decreasing trend as the particle size diminished. To clarify this, more laboratory experiments are needed to experimentally determine the particle charging efficiency in the sub- $10 \mathrm{~nm}$ size range.

A crucial part of the ion-DMPS is the radioactive charger in front of the instrument. Since our aim was to determine the charging state, i.e. the excess or deficit of electrical charges in ultra-fine particles, the radioactive source in the system has to be strong enough to efficiently neutralize the charging state of the sampled particles to equilibrium conditions. This is needed in the calculation of over/undercharging state as a reference concentration. To test this, higher than typical atmospheric concentrations of negatively charged silver particles utilizing the laboratory setup were generated. The ion-DMPS distributions measured with the charger and positive polarity (i.e. neutralized negative particles) agreed well with a parameterization by Wiedensohler (1988). This indicates that the charger was in a working order.

\subsection{Balanced Scanning Mobility Sizer (BSMA)}

In addition to ion-DMPS, we carried out ion measurements using a Balanced Scanning Mobility Sizer (BSMA) (Tammet, 2004, 2006). The Balanced Scanning Mobility Analyzer, manufactured by Airel Ltd., Estonia, consists of two plain aspiration-type Differential Mobility Analyzers, one for positive and the other for negative ions. The two aspiration condensers are connected as a balanced bridge circuit that allows continuous variation of the driving voltage and scanning of the mobility distribution of charged clusters and 

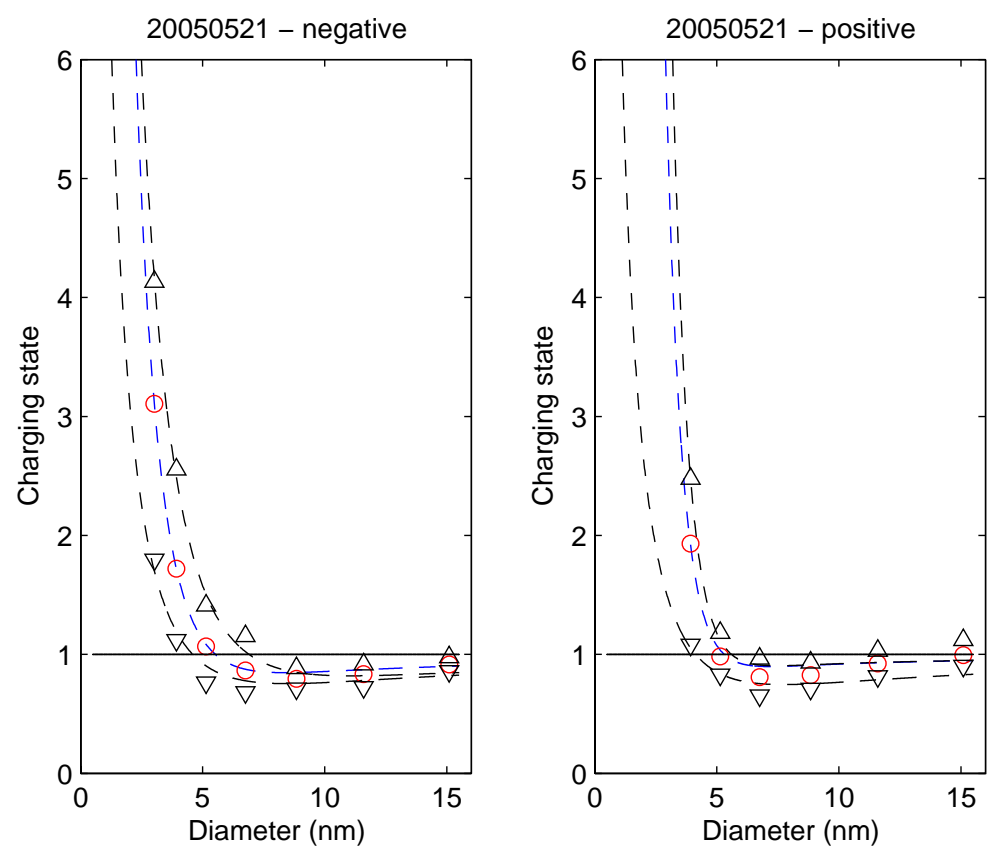

Fig. 5. Charging state during 21 May 2005 - overcharging occur for both negative (left panel) and positive (right panel) polarities. Red circles represent median charging state as a function of particle size obtained from Ion-DMPS. The black triangles depict $25 \%$ (downward triangles) and $75 \%$ (upward triangles) percentiles of the charging state. The lines are optimized least squares fits through median, $25 \%$ and $75 \%$ percentile points using Eq. (1).

nanoparticles. A large airflow rate of 441 per second helps to suppress the loss of air ions in the inlet of the instrument. The inlet can be closed or opened for ions using a controlled electrostatic filter, and the background signal is eliminated by making every other scan with a closed inlet. A mobility distribution is calculated according to the results of 9 scans performed over $3 \mathrm{~min}$. The electric mobility range of 0.032 $3.2 \mathrm{~cm}^{2} \mathrm{~V}^{-1} \mathrm{~s}^{-1}$ is logarithmically uniformly divided into 16 fractions. The corresponding size distribution is presented by 10 fractions, logarithmically equally distributed in a diameter range of $0.4-7.5 \mathrm{~nm}$.

\section{Data treatment and analysis}

\subsection{Interpretation of ion-DMPS-results}

Figure 3 represents schematically four different cases of nucleation and how they are observed by an ion-DMPS.

In case of neutral nucleation all particles are formed electrically neutral from nucleating vapors (Fig. 3, second row), whereas in ion-induced particle formation nucleation takes place on pre-existing cluster ions so that all freshly-formed particles carry one positive or negative elementary charge (Fig. 3, first row). When the particles grow bigger, they tend to reach charge equilibrium. In addition to pure neutral or ion-induced nucleation, different combinations of these two mechanisms are also possible. The third row in Fig. 3 repre- sents the case where ion-induced nucleation dominates over neutral nucleation, whereas in the fourth row of Fig. 3 neutral nucleation dominates over ion-induced nucleation.

In addition to the cases presented in Fig. 3, it is also possible that positive and negative ions behave in a different way, i.e. ion-induced nucleation can have a charge preference (Kusaka et al., 1995; Lovejoy et al., 2004). For that reason we measured both the polarities. Common to all different nucleation combinations, the only way to receive an overcharging is that at least some fraction of the new particles have originated from ion-induced nucleation.

An example of inverted Ion-DMPS data together with conventional DMPS-data is shown in Fig. 4. The concentration of negative natural particles was higher during the first hour of the event than the corresponding concentrations after the ambient particles were neutralized with the radioactive source (Fig. 4c and d, respectively). In other words, fresh atmospheric particles during this day carried excess negative charges compared with the equilibrium state. This is an indication of the participation of ions in the first steps of the particle formation process. Also positive particles were slightly overcharged.

One way to analyze the possible existence of ion-induced nucleation is to calculate the ratio between the natural to neutralized particle concentrations (right column in Fig. 3). If the ratio is $>1$, the particles are overcharged compared to the equilibrium state. On the other hand, if the ratio is $<1$, 

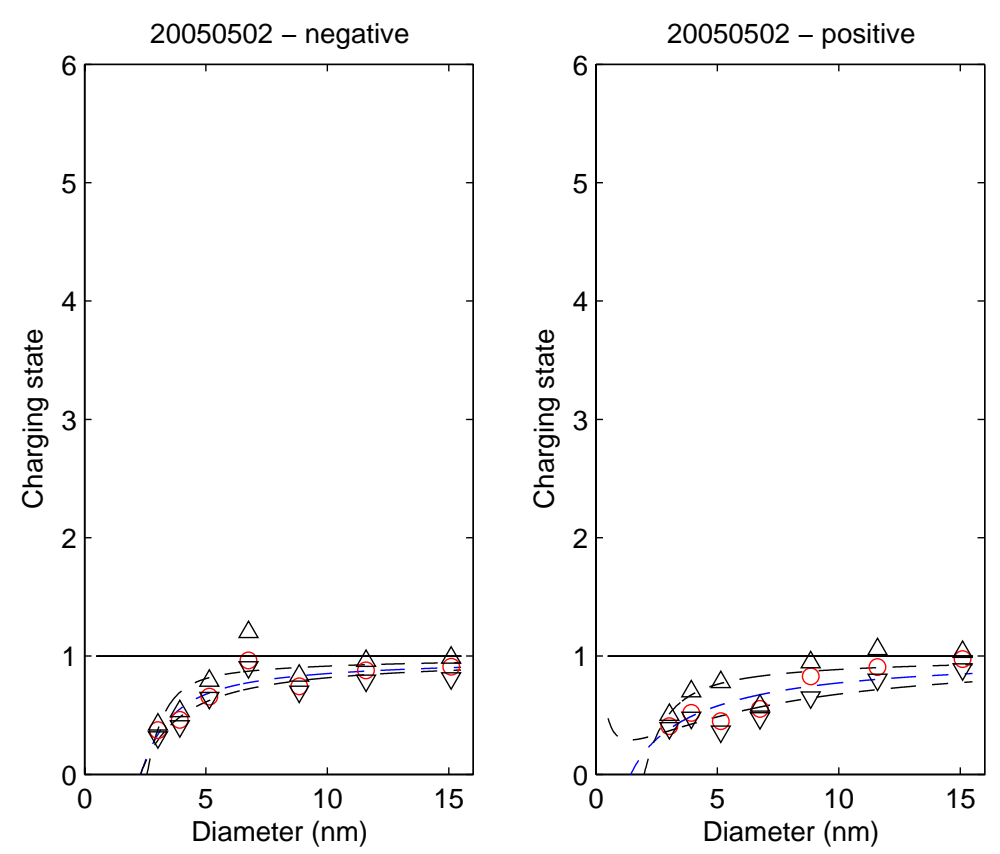

Fig. 6. Charging state during 2 May 2005 - undercharging occur for both negative (left panel) and positive (right panel) polarities. Red circles represent median charging state as a function of particle size obtained from Ion-DMPS. The black triangles depict $25 \%$ (downward triangles) and $75 \%$ (upward triangles) percentiles of the charging state. The lines are optimized least squares fits through median, $25 \%$ and $75 \%$ percentile points using Eq. (1).

the particles are undercharged. The benefit in using this ratio and one single inlet lies in the fact that it allows us to avoid systematic errors due to losses within the inlet structure.

By dividing the natural ion concentration (only values over $0.1 \mathrm{~cm}^{-3}$ are used) by the neutralized ion concentration for each diameter and time, we obtain the charging state as a function of time and particle size. This state is averaged over the nucleation period for each diameter. Two example cases are shown in Figs. 5 and 6. In Fig. 5 (21 May 2005) one can observe an overcharged nucleation event for both positive and negative ions, whereas in Fig. 6 (2 May 2005) particles of both polarities are undercharged.

An example of the time behavior of the charging state is shown in Fig. 7. As shown in Fig. 7 the charging states of 5 and $7 \mathrm{~nm}$ particles are vary within a factor 2 from unity during the day. On the other hand the charging state of $3 \mathrm{~nm}$ particles vary a lot from 7 to 1 . It is also decreasing during the day indicating that ion clusters will first activate or ion induced nucleation are more important before noon than later.

\section{Results from atmospheric measurements}

We measured with our ion-DMPS at the SMEAR II (Station for Measuring Forest Ecosystem-Atmosphere Relations, Vesala et al. (1998); Kulmala et al. (2001)) located at Hyytiälä Forestry field station during spring 2005 as a part of BACCI-QUEST intensive field campaign. Between 30 March and 18 May, the device was located in the main cottage of the station; the inlet was at $2 \mathrm{~m}$ height. From 18 May, 2005 onwards, the instrument was located in an another cottage some $150 \mathrm{~m}$ south from the main cottage. At this location the sample was drawn from $9 \mathrm{~m}$ above ground level with a high flow rate $\left(\sim 1001 \mathrm{~min}^{-1}\right)$ and distributed to ion-DMPS and many other aerosol instruments. The functionality of the instrument was verified twice during the field campaign with ammonium sulphate particles. The results were in agreement with laboratory measurements presented in Fig. 2.

\subsection{General features of nucleation mode charging state}

The analysis was made for those days during which we were able to use data from ion-DMPS, BSMA and DMPS.

Figure 8 shows the charging state of different-size particles during all the event days observed, 34 days in total. One can see that negative ions tended to be overcharged for smaller diameters and close to equilibrium for bigger particles. The same tendency was observed for positive ions. However, for one day (2 May 2005, see also Fig. 6) the positive and the negative ions were undercharged at lower particle sizes reaching equilibrium at larger sizes. Compared with event days, the particle charging state seemed to behave quite differently during the five non-event days observed (Fig. 8). One must remember, however, that the charging state of sub$5 \mathrm{~nm}$ particles could not be determined during the non-event 

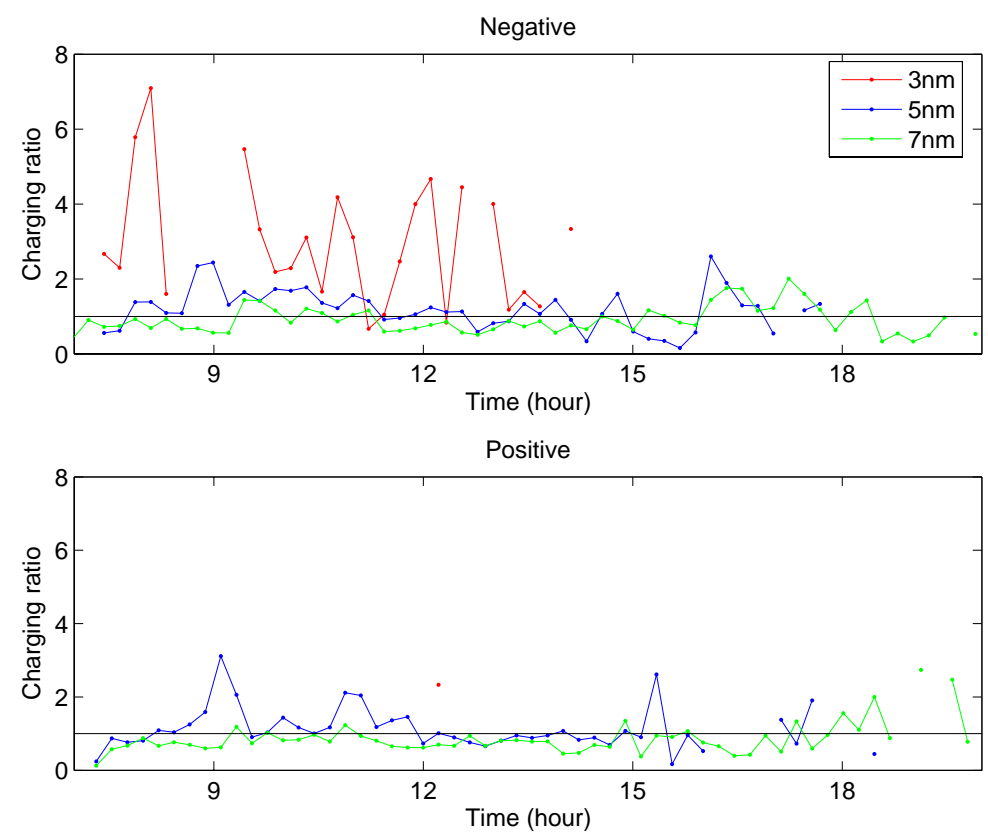

Fig. 7. Time development of charging state during the event day 21 May 2005 for 3, 5 and $7 \mathrm{~nm}$ particle sizes for negative (upper panel) and positive (lower panel) polarities.
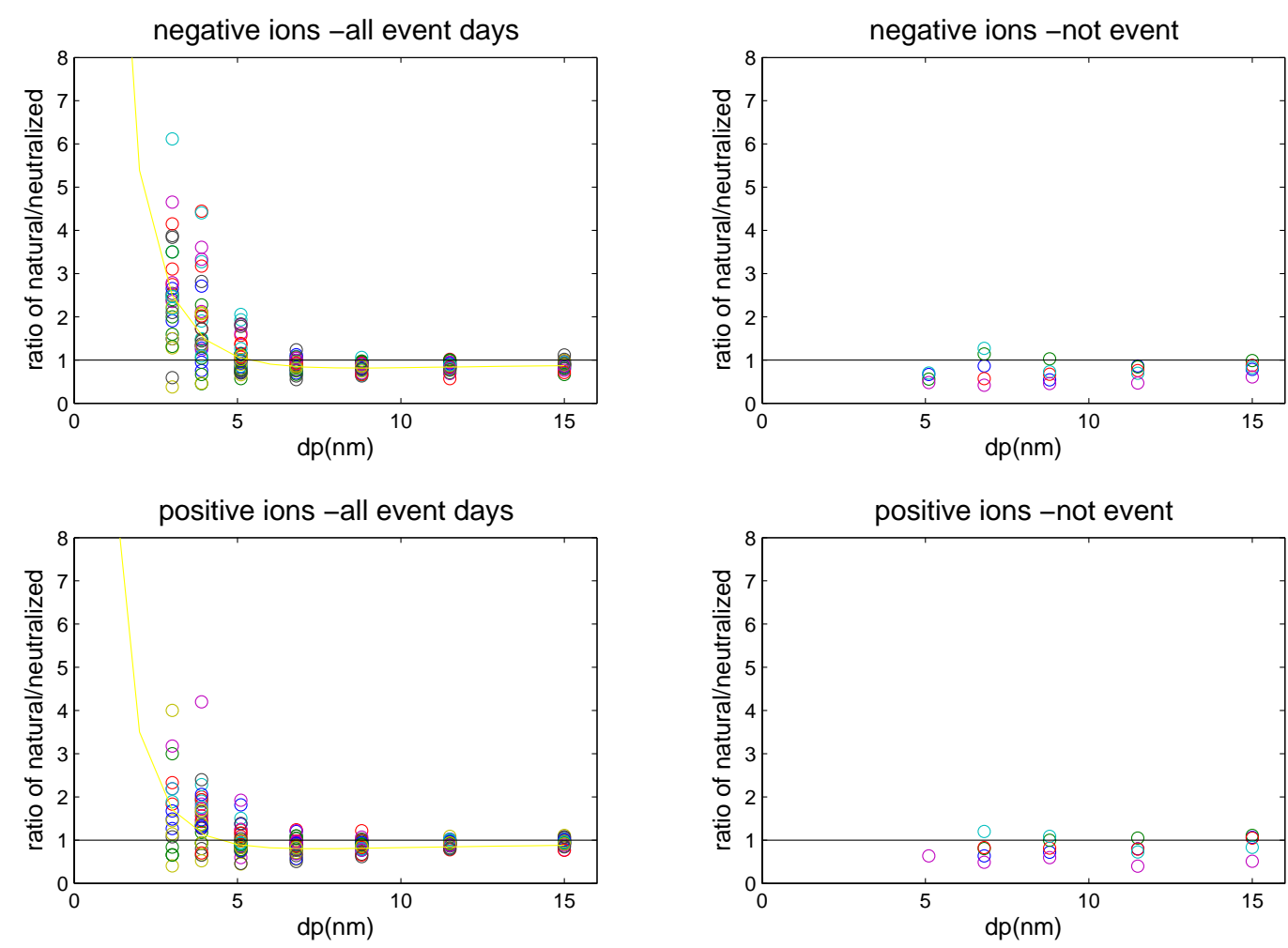

Fig. 8. On the left, median ratio for all considered new particle formation event days for both negative (upper right panel) and positive (lower right panel) polarities (solid line). Individual points represent charging state as a function of particle size obtained from the ion-DMPS during all new particle formation event days considered in this study. On the right, median charging ratio for a witness sample of 5 non-event days as a function of particle size for both negative (upper right panel) and positive (lower right panel) polarities. 
Table 1. Parameters describing the charging state for negative polarity during selected nucleation event days. Charging state $\mathrm{S}$ at $1 \mathrm{~nm}$, $1.5 \mathrm{~nm}$ and $2 \mathrm{~nm}$ and parameter $\mathrm{K}$ are optimized in least squares sense to ion-DMPS data, when concentrations below $0.1 \mathrm{~cm}^{-3}$ are omitted.

\begin{tabular}{lcccccc}
\hline Date & $\mathrm{K}\left[\mathrm{nm}^{-1}\right]$ & upper limit & lower limit & S@ 1nm & S@ 1.5nm & S@ 2nm \\
\hline 20050413 & 0.5 & 0.6 & 0.3 & 12.6 & 6.6 & 4 \\
20050417 & 1.5 & 1.1 & 3.2 & 304.1 & 98.5 & 36.2 \\
20050418 & 1 & 0.9 & 1.2 & 89.5 & 36.7 & 17.1 \\
20050420 & 0.9 & 1.3 & 0.1 & 60.1 & 25.9 & 12.7 \\
20050424 & 0.8 & 10 & 0.2 & 3.4 & 1.8 & 1.2 \\
20050430 & 1.9 & 10 & 0.9 & -2130.1 & -543.7 & -155.7 \\
20050502 & 0.7 & 1 & 0.4 & -2.5 & -1 & -0.3 \\
20050503 & 1.5 & 1.2 & 0.1 & 210.2 & 65.3 & 23.1 \\
20050508 & 1.3 & 2.6 & 0.2 & 95.7 & 33.5 & 13.5 \\
20050510 & 1.3 & 0.9 & 1 & 107.6 & 38.5 & 15.8 \\
20050511 & 0.9 & 0.6 & 1.7 & 60.6 & 26.6 & 13.3 \\
20050512 & 0.7 & 0.4 & 0.7 & 25.7 & 12.1 & 6.5 \\
20050513 & 1.1 & 0.9 & 0.3 & 48.1 & 18.6 & 8.3 \\
20050514 & 0.8 & 0.5 & 0.3 & 11.6 & 5.6 & 3.1 \\
20050516 & 0.8 & 0.7 & 0.2 & 27 & 12.6 & 6.7 \\
20050520 & 0.5 & 0.6 & 0.2 & 6.8 & 3.8 & 2.5 \\
20050521 & 0.7 & 0.5 & 0.6 & 29.2 & 14.2 & 7.9 \\
20050524 & 0.6 & 0.5 & 0.1 & 65.8 & 32.3 & 18 \\
20050527 & 0.2 & 0.1 & 0.2 & 10.7 & 6.4 & 4.3 \\
20050604 & 0.8 & 0.6 & 0.1 & 93.8 & 42.6 & 21.9 \\
\hline Min & 0.2 & 0.1 & 0.1 & -2130.1 & -543.7 & -155.7 \\
Max & 1.9 & 10 & 3.2 & 304.1 & 98.5 & 36.2 \\
Median & 0.8 & 0.8 & 0.3 & 38.7 & 16.4 & 8.1 \\
\hline
\end{tabular}

days due to absence of these particles from the measured size spectra.

By starting from detailed charge balance equations, Kerminen et al. (2007) ${ }^{1}$ derived an analytical formula that gives the charging state $S$ of a growing nuclei population as a function of particle diameter, $d_{p}$ :

$S\left(d_{p}\right)=1-\frac{1}{K d_{p}}+\frac{1+\left(S_{0}-1\right) K d_{0}}{K d_{p}} \exp \left(-K\left(d_{p}-d_{0}\right)\right)(1)$

Here $S_{0}$ is the charging state at some reference diameter $d_{0}$, and $K$ is a parameter given by

$K=\frac{\alpha N_{ \pm}^{C}}{G R\left(d_{p}\right)}$

where $\alpha$ is the ion-ion recombination coefficient, $G R$ is the nuclei growth rate and $N_{ \pm}^{C}$ is the concentration of positive or negative cluster ions (assumed to be the same when Eq. (1) was derived).

Equation (1) demonstrates that the rate at which the growing nuclei population approaches charge equilibrium $(S=1)$ depends only on the parameter $K$. When the nuclei have

\footnotetext{
${ }^{1}$ Kerminen, V.-M., Anttila, T., Petäjä, T., Laakso, L., Gagné, S., Lehtinen, K. E. J., and Kulmala, M.: Charging state of the atmospheric nucleation mode: implications for separating neutral and ion-induced nucleation, J. Geophys. Res., to be submitted, 2007.
}

reached measurable sizes ( $>3 \mathrm{~nm}$ diameter), information about their initial charging state is completely lost if $K$ is larger than about $2-4 \mathrm{~nm}^{-1}$. In such cases there is no way of getting information about the contribution of ion-induced nucleation based on ion-DMPS measurements alone.

In moderately polluted environments such as the one considered here, the error in S predicted by Eq. (1) is usually below 10-20\% (Kerminen et al., 2007) ${ }^{1}$. Larger errors may emerge if the total number concentration of nucleation mode particles is much larger than the cluster ion concentration, if the value of $K$ varies with time or nuclei size, or if the initial charging state of the nuclei population is larger than about $50-100$, i.e. the nuclei were born dominantly by ion-induced nucleation.

The parameter $K$ can be determined in two ways: 1) by fitting a curve given by Eq. (1) into experimental data obtained from ion-DMPS measurements or, 2) by calculating it directly from measured ion cluster number concentrations and nuclei grow rates. Examples of the first approach are shown in Figs. 5 and 6 for overcharged and undercharged nucleation events, respectively. The fittings were made by minimizing the distance between the experimental points and the curved given by Eq. (1). We can see that the fitted curves capture quite well the measured size dependencies of the nuclei charging states as well as their variability over each particle formation event. The second approach can be applied only 
Table 2. Parameters describing the charging state for positive polarity during selected nucleation event days. Charging state $\mathrm{S}$ at $1 \mathrm{~nm}$, $1.5 \mathrm{~nm}$ and $2 \mathrm{~nm}$ and parameter $\mathrm{K}$ are optimized in least squares sense to ion-DMPS data, when concentrations below $0.1 \mathrm{~cm}^{-3}$ are omitted.

\begin{tabular}{|c|c|c|c|c|c|c|}
\hline Date & $\mathrm{K}\left[\mathrm{nm}^{-1}\right]$ & upper limit & lower limit & $\mathrm{S} @ 1 \mathrm{~nm}$ & $\mathrm{~S} @ 1.5 \mathrm{~nm}$ & $\mathrm{~S} @ 2 \mathrm{~nm}$ \\
\hline 20050413 & 0.5 & 0.3 & 0.4 & 8.1 & 4.4 & 2.8 \\
\hline 20050414 & 1 & 4.2 & 0.5 & 4.8 & 2.2 & 1.4 \\
\hline 20050417 & 0.8 & 2.6 & 0.2 & 25.8 & 11.9 & 6.3 \\
\hline 20050424 & 1.6 & 1.7 & 0.3 & 2137.4 & 630 & 209.3 \\
\hline 20050425 & 1.8 & 2.5 & 0.3 & 342.1 & 94 & 29.4 \\
\hline 20050427 & 1.5 & 1.5 & 0.3 & 317 & 101.2 & 36.6 \\
\hline 20050502 & 0.4 & 0.7 & 0.3 & -0.3 & 0 & 0.2 \\
\hline 20050503 & 0.3 & 0.7 & 0.2 & 3.4 & 2.1 & 1.5 \\
\hline 20050508 & 0.9 & 0.6 & 0.2 & 17.1 & 7.6 & 4 \\
\hline 20050511 & 0.5 & 0.1 & 0.7 & 13.3 & 7 & 4.3 \\
\hline 20050513 & 1.5 & 0.8 & 2.5 & 143.9 & 46.2 & 17 \\
\hline 20050514 & 0.6 & 0.3 & 0.3 & 10.3 & 5.3 & 3.2 \\
\hline 20050516 & 0.8 & 2.7 & 0.2 & 20.9 & 9.8 & 5.3 \\
\hline 20050517 & 0.5 & 0.5 & 0.2 & 10.4 & 5.6 & 3.4 \\
\hline 20050520 & 1.4 & 10 & 0.3 & -3.6 & -0.8 & 0.1 \\
\hline 20050521 & 1.2 & 1.4 & 0.4 & 156.3 & 57 & 23.6 \\
\hline 20050522 & 0.5 & 0.2 & 0.5 & 33.9 & 17.4 & 10.1 \\
\hline 20050527 & 0.7 & 3 & 0.3 & 8.7 & 4.3 & 2.5 \\
\hline 20050531 & 0.5 & 0.4 & 0.2 & 21.9 & 11.4 & 6.8 \\
\hline 20050604 & 0.6 & 10 & 0.1 & 5.5 & 3 & 1.9 \\
\hline 20050608 & 1.3 & 1.6 & 0.3 & 147.2 & 52.7 & 21.5 \\
\hline 20050609 & 0.7 & 0.5 & 1.2 & 110.2 & 51.8 & 27.5 \\
\hline 20050610 & 1 & 2.3 & 0.2 & 62.5 & 26 & 12.3 \\
\hline 20050611 & 1 & 1.1 & 0.2 & 133.3 & 53.1 & 24 \\
\hline Min & 0.3 & 0.1 & 0.1 & -3.6 & -0.8 & 0.1 \\
\hline Max & 1.8 & 10 & 2.5 & 2137 & 630.0 & 209.3 \\
\hline Median & 0.8 & 1.3 & 0.3 & 21.4 & 10.6 & 5.8 \\
\hline
\end{tabular}

if time-resolved air ion and aerosol particle number size distribution measurements are available. Even then, the error in the calculated values of $K$ might be considerable.

The fitting procedure was repeated for all the 34 nucleation event days presented in Fig. 8. Days with median particle number concentrations remaining below $0.1 \mathrm{~cm}^{-3}$ in several size ranges were left out of the analysis because of data quality issues. Once the fittings were obtained, we further omitted the days for which the fitted value of $K$ was larger than $2 \mathrm{~nm}^{-1}$ or deviated by more than a factor of three from the calculated value of $K$ based on BSMA and DMPS measurements. By this way, we roughly ruled out the nucleation events for which the information about the initial nuclei charging state may have been lost (a large value of $K$ ), as well as the events for which the fitting most likely failed for some unknown reason.

The days that passed the above criteria have been summarized in Tables 1 and 2 for negatively and positively charged particles, respectively. Plotted in these tables are the fitted values of $K$, their "upper" and "lower" estimates, and the corresponding values of the charging state $S$ extrapolated down to $1.5-\mathrm{nm}$ and 2-nm sizes of particle mobility diam- eter. This is the probable size range where the nucleation took place. Note that the "upper" and "lower" values of $K$ and $S$ do not present error estimates but rather reflect the data variability over each nucleation event. We may see that some of the extrapolated values of $S$ are negative. This reflects the sensitivity of the fits to the exact location of measurement points in cases with significant undercharging, i.e. when neutral nucleation completely dominates the initial aerosol formation. Likewise, although the values of $S$ in excess of about 50-100 are indicative of the dominance of ion-induced nucleation, the absolute values of $S$ can not be trusted in such cases.

In estimating the value of $S$ at 1.5 and $2 \mathrm{~nm}$, we assumed that the value of $K$ was the same below and above $3 \mathrm{~nm}$, i.e. the one obtained from the fittings. This may not be true, since the growth rates of $1-3 \mathrm{~nm}$ particles might be larger or smaller than those of $>3 \mathrm{~nm}$ particles. The former might result from the possible effect of enhanced condensation growth of charged clusters below $3 \mathrm{~nm}$ (e.g. Yu and Turco (2000)). Observations in Hyytiälä indicate, however, that the nuclei growth rate increases rather than decreases with increasing particle size, with typical growth rates being 

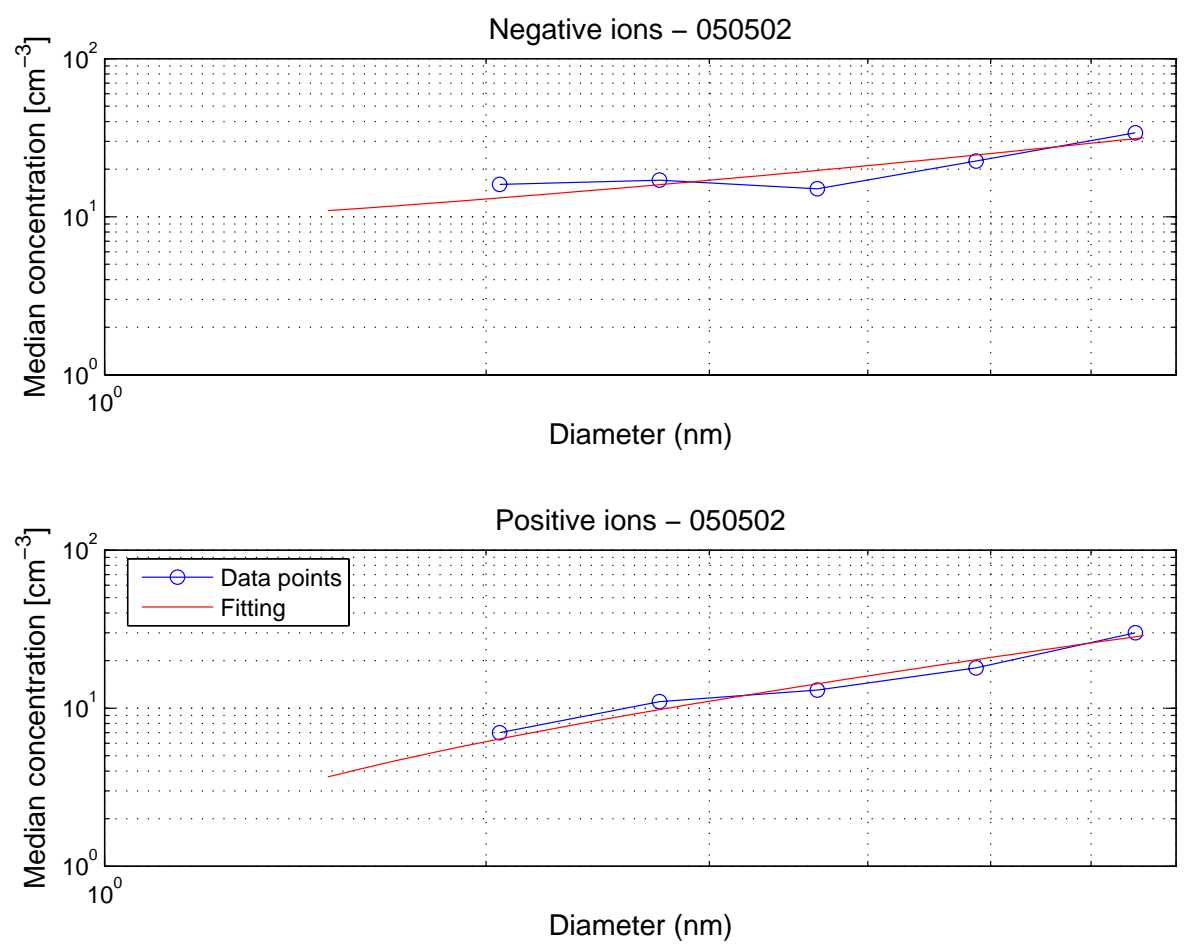

Fig. 9. Example of fittings of BSMA concentration data obtained 2 May 2005 for negative (upper panel) and positive ions (lower panel).

higher by a factor $2-3$ at the 5 -nm size compared with the 2-nm size (Hirsikko et al., 2005). If this were the case, the values of $S$ at 1.5 and $2 \mathrm{~nm}$ would in reality be larger than those given in Tables 1 and 2.

Keeping in mind the uncertainties resulting from the data variability and the value of $K$ below $3 \mathrm{~nm}$, it can be concluded that the a large fraction of the days considered here seemed to have either negligible $(S<1$ at $1.5 \mathrm{~nm})$ or relatively small $(S<10$ at $1.5 \mathrm{~nm})$ contribution from ion-induced nucleation. This is consistent with the recent results by Iida et al. (2006) based on charging state measurements over the 3$5 \mathrm{~nm}$ size range conducted in Boulder, Colorado. However, contrary to observations by Iida et al. (2006), we had also a few days during which the contribution of ion-induced nucleation may have been significant or even dominant $(S>50$ at $1.5 \mathrm{~nm}$ ). Estimating the exact contribution of ion-induced nucleation on such days would require better knowledge about the actual size at which nuclei were formed in the atmosphere, as well as knowing more accurately how rapidly they grew into sizes measurable by the Ion-DMPS.

\subsection{Comparison with BSMA measurements}

We also compared our results from the Ion-DMPS with observations from the BSMA. This was done by calculating the average concentration over the nucleation period for each size and then fitting a line to the data points (see Fig. 9 and the first column in Fig. 3). We have then three different pos-

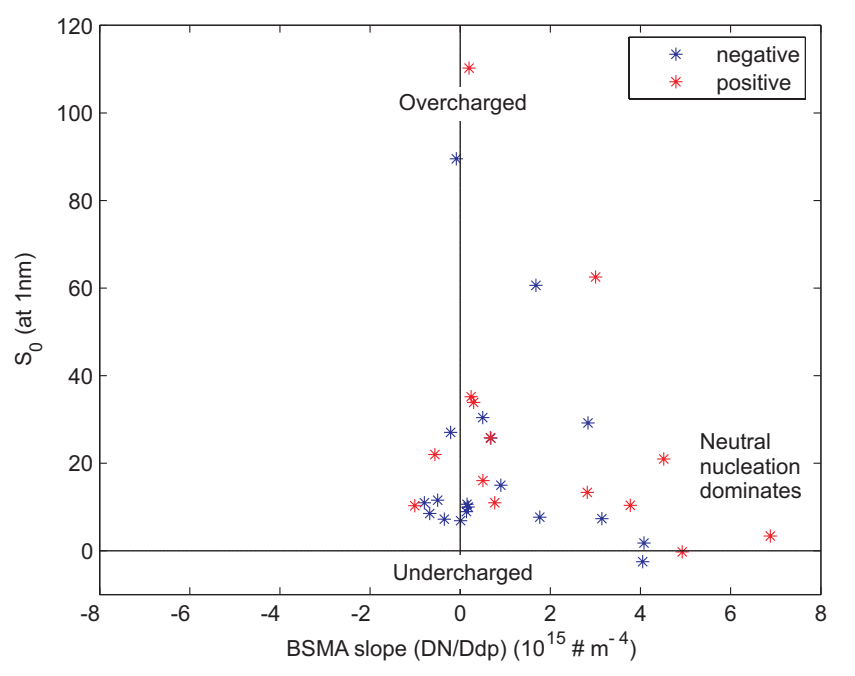

Fig. 10. Comparison between BSMA and Ion-DMPS results. $x^{-}$ axis show the slope of fittings done to ion concentrations obtained from BSMA whereas y-axis show the value $S_{0}$. Point with high positive slope and low charged fractions indicate domination of neutral nucleation.

sibilities: 1) the concentration of ions decreases (negative slope), 2) the concentration of ions is constant (zero slope), or 3 ) the concentration of ions increases as a function of size (positive slope). We can now analyze these cases more in detail: 
- Case 1: We can obtain this situation with two different ways. If we have ion-induced nucleation, we have high concentration of ions at small sizes. When the particles grow bigger, charged particles get neutralized and their concentration decreases. In addition, concentration of charged particles decreases due to coagulation scavenging. However, another possibility for decreasing charged particle concentration is neutral nucleation. If we have high neutral nucleation rate, part of the particles are charged. Due to coagulation loss, number of all particles rapidly decreases, and despite increasing charging probability with increasing size, overall effect can be decreasing of charged particles as a function of size. Thus, in this case we can not say anything about nucleation mechanism.

- Case 2: Same arguments as in Case 1 apply and we can not say anything about the nucleation mechanism.

- Case 3: If the concentration of charged particles increases with increasing size, neutral nucleation have to dominate.

Figure 10 shows the fitted charging state $S 0$ at $1 \mathrm{~nm}$ as a function of the slope of BSMA fittings. The results indicate that the days with high positive BSMA slope values, particles are clearly less charged and thus neutral nucleation dominates.

\section{Conclusions}

In this study, we introduced a new DMPS setup which gives information on nucleation processes. We also showed experimental data from 34 new particle formation days from Hyytiälä. Some of the days were clearly overcharged indicating contribution of ion-induced nucleation to new particle formation, whereas some days were undercharged and thus neutral nucleation dominated. The behavior of negative ions differed from that of positive ones; there were usually more negative overcharging compared with positive overcharging. Our results indicate clearly that ion-induced nucleation takes place in the atmosphere and that it has a clear sign preference in favor of negative ions. During a large fraction of days considered here, the contribution of ion-induced nucleation to the total nucleation rate was either negligible or relatively small. More exact estimates on relative roles of ion- and neutral nucleation in boreal forest would, however, require more precise knowledge on the growth rate of newly formed particles to Ion-DMPS size range.

In the future, we will utilize this experimental setup for calculating quantitatively the contribution of ion-induced nucleation on boreal new particle formation episodes for one full year of measurements.
Acknowledgements. This work was partly supported by Academy of Finland through Research Unit on Biosphere-Aerosol-CloudClimate Interactions (BACCI) and the EU project "Quantification of Aerosol Nucleation in the European Boundary Layer" (QUEST), EVK2-CT2001-00127). P. Pihkala and E. Siivola are acknowledged for constructing the charger and related electronics, respectively. V. Hiltunen and H. Laakso are acknowledged for their work keeping the instrument running in SMEAR II. Constructive criticism and suggestions from the referees are acknowledged. Their efforts improved the quality of the manuscript substantially.

Edited by: A. Laaksonen

\section{References}

Aalto, P., Hämeri, K., Becker, E., Weber, R., Salm, J., Mäkelä, J. M., Hoell, C., O’Dowd, C. D., Karlsson, H., Hansson, H.C., Väkevä, M., Koponen, I. K., Buzorius, G., and Kulmala, M.: Physical characterization of aerosol particles during nucleation events, Tellus, 53B, 344-358, 2001.

Baron, P. and Willeke, K.: Aerosol Measurement: Principles, Techniques, and Applications, 2nd edition, John Wiley and Sons, 2001.

Eichkorn, S., Wilhelm, S., Aufmhoff, H., Wohlfrom, K., and Arnold, F.: Cosmic ray-induced aerosol formation: First evidence from aircraft-based ion mass spectrometer measurements, Geophys. Res. Lett., 29, 14, doi:10.1029/2002GL015044, 2002.

Eisele, F. L., Lovejoy, E. R., Kosciuch, E., Moore, K., Mauldin III, R., Smith, J.-N., McMurry, P., and Iida, K.: Negative atmospheric ions and their potential role in ion-induced nucleation, $\mathrm{J}$. Geophys. Res., 111, D04305, doi:10.1029/2005JD006568, 2006.

Flagan, R.: History of Electrical Aerosol Measurements, Aerosol Sci. Technol., 28, 301-380, 1998.

Fuchs, N. A. and Sutugin, A. G.: Highly dispersed aerosols., Ann Arbour Science Publishers, Ann Arbour, London, 1970.

Hirsikko, A., Laakso, L., Hõrrak, U., Aalto, P., Kerminen, V.-M., and Kulmala, M.: Annual and size dependent variation of growth rates and ion concentrations in boreal forest, Boreal Environ. Res., 10, 357-369, 2005.

Hoppel, W. and Frick, G.: Ion-aerosol attachment coefficients and steady-state charge distribution on aerosols in a bipolar environment, Aerosol Sci. Technol., 5, 1-21, 1986.

Hoppel, W. A., Frick, G. M., Fitzgerald, J. W., and Larson, R. E.: Marine boundary layer measurements of new particle formation and the effects nonprecipitating clouds have on aerosol size distribution, J. Geophys. Res., 99, 14 443-14 459, 1994.

Hussin, A., Scheibel, H., Becker, K., and Porstendorfer, J.: Bipolar diffusion charging of aerosol particles - I: Experimental results within the diameter range 4-30 nm, J. Aerosol Sci., 14, 671-677, 1983.

Iida, K., Stolzenburg, M., McMurry, P., Dunn, M. J., Smith, J. N., Eisele, F., and Keady, P.: Contribution of ion-induced nucleation to new particle formation: Methodology and its application to atmospheric observations in Boulder, Colorado, J. Geophys. Res., 111, D23201, doi:10.1029/2006JD007167, 2006.

Jokinen, V. and Mäkelä, J. M.: Closed loop arrangement with critical orifice for DMA sheath/excess flow system, J. Aerosol Sci., 28, 643-648, 1997. 
Kulmala, M., Pirjola, L., and Mäkelä, J. M.: Stable sulphate clusters as a source of new atmospheric particles, Nature, 404, 66-69, 2000.

Kulmala, M., Hämeri, K., Aalto, P., Mäkelä, J., Pirjola, L., Nilsson, E. D., Buzorius, G., Rannik, Ü., Dal Maso, M., Seidl, W., Hoffmann, T., Janson, R., Hansson, H.-C., Viisanen, Y., Laaksonen, A., and O'Dowd, C.: Overview of the international project on biogenic aerosol formation in the boreal forest (BIOFOR), Tellus B, 53, 324-343, 2001.

Kulmala, M., Vehkamäki, H., Petäjä, T., Dal Maso, M., Lauri, A., Kerminen, V.-M., Birmili, W., and McMurry, P.: Formation and growth rates of ultrafine atmospheric particles: a review of observations, J. Aerosol Sci., 35, 143-176, 2004.

Kulmala, M., Lehtinen, K. E. J., and Laaksonen, A.: Cluster activation theory as an explanation of the linear dependence between formation rate of $3 \mathrm{~nm}$ particles and sulphuric acid concentration, Atmos. Chem. Phys., 6, 787-793, 2006, http://www.atmos-chem-phys.net/6/787/2006/.

Kusaka, I., Wang, Z.-G., and Seinfeld, J. H.: Ion-induced nucleation, II, Polarizable multipolar molecules, J. Chem. Phys., 103, 8993-9009, 1995.

Laakso, L., Mäkelä, J., Pirjola, L., and Kulmala, M.: Model studies on ion-induced nucleation in the atmosphere, J. Geophys. Res., 107, 4427, doi:10.1029/2002JD, 2002.

Laakso, L., Anttila, T., Lehtinen, K., Aalto, P., Kulmala, M., Hõrrak, U., Paatero, J., Hanke, M., and Arnold, F.: Kinetic nucleation and ions in boreal particle formation events, Atmos. Chem. Phys., 4, 2353-2366, 2004, http://www.atmos-chem-phys.net/4/2353/2004/.

Lovejoy, E., Curtius, J., and Froyd, K.: Atmospheric ion-induced nucleation of sulfuric acid and water, J. Geophys. Res., 109, D08204, doi:10.1029/2003JD004 460, 2004.

Misaki, M.: A method of measuring the ion spectrum, Pap. Meteorol. Geophys., 1, 313-318, 1950.

Misaki, M.: Studies on the atmospheric ion spectrum (I) - Procedures of experiments and data analysis, Pap. Meteorol. Geophys., 12, 247-260, 1961.

Mäkelä, J. M., Salm, J., Smirnov, V. V., Koponen, I., Paatero, J., and Pronin, A. A.: Electrical charging state of fine and ultrafine particles in boreal forest air, J. Aerosol Sci., 32, S149-S150, 2003.

Reischl, G., Mäkelä, J., Karch, R., and Necid, J.: Bipolar charging of ultrafine particles in the size range below $10 \mathrm{~nm}$, J. Aerosol Sci., 27, 931-949, 1996.
Stolzenburg, M. and McMurry, P.: An ultrafine aerosol condensation nucleus counter, Aerosol Sci. Technol., 14, 48-65, 1991.

Tammet, H.: Balanced Scanning Mobility Analyzer, in: Proceedings of 16th International Conference on Nucleation \& Atmospheric Aerosols (ICNAA) in Kyoto, edited by: Kasahara, M. and Kulmala, M., 294-297, 2004.

Tammet, H.: Continuous scanning of the mobility and size distribution of charged clusters and nanometer particles in atmospheric air and the Balanced Scanning Mobility Analyzer BSMA, Atmos. Res., 82, 523-535, 2006.

Vana, M., Tamm, E., Hõrrak, U., Mirme, A., Tammet, H., Laakso, L., Aalto, P. P., and Kulmala, M.: Charging state of atmospheric nanoparticles during the nucleation burst events, Atmos. Res., 82, 536-546, 2006.

Vesala, T., Haataja, J., Aalto, P., Altimir, N., Buzorius, G., Garam, E., Hämeri, K., Ilvesniemi, H., Jokinen, V., Keronen, P., Lahti, T., Markkanen, T., Mäkelä, J., Nikinmaa, E., Palmroth, S., Palva, L., Pohja, T., Pumpanen, J., Rannik, U., Siivola, E., Ylitalo, H., Hari, P., and Kulmala, M.: Long-term field measurements of atmosphere-surface interactions in boreal forest combining forest ecology, micrometeorology, aerosol physics and atmospheric chemistry, Trends in Heat, Mass \& Momentum Transfer, 4, 17 35, 1998.

Weber, R. J., McMurry, P. H., Eisele, F. L., and Tanner, D. J.: Measurements of expected nucleation precursor species and 3-500nm diameter particles at Mauna Loa observatory, Hawaii, J. Atmos. Sci., 52, 2242-2257, 1995.

Weber, R. J., Marti, J., McMurry, P. H., Eisele, F., Tanner, D. J., and Jefferson, A.: Measured atmospheric new particle formation rates: implications for nucleation mechanisms, Chem. Eng. Comm, 151, 53-64, 1996.

Wiedensohler, A.: An approximation of the bipolar charge distribution for particles in the submicron range, J. Aerosol Sci., 19, 387-389, 1988.

Winklmayr, W., Reischl, G. P., Lindner, A., and Berner, A.: A new electromobility spectrometer for the measurement of aerosol size distributions in the size range from 1 to $1000 \mathrm{~nm}$, J. Aerosol Sci., 22, 289-296, 1991.

Yu, F. and Turco, R. P.: Ultrafine aerosol formation via ionmediated nucleation, Geophys. Res. Lett., 27, 883-886, 2000. 